\title{
Nurses' Medication Administration Errors at Medical Surgical Units
}

\author{
Kennedy Nyongesa Simiyu ${ }^{1, *}$, Haneya Mohammad El-Banna ${ }^{2}$, Mervat Abdel Fattah $^{2}$, \\ Lilian Adhiambo Omondi ${ }^{3}$
}

${ }^{1}$ Department of Nursing, Moi Teaching and Referral Hospital, Eldoret, Kenya

${ }^{2}$ Faculty of Nursing, Department of Medical Surgical Nursing, Alexandria University, Alexandria, Egypt

${ }^{3}$ School of Nursing, Department of Medical Surgical Nursing, University of Nairobi, Nairobi, Kenya

\section{Email address:}

kennedysimiyu@mtrh.go.ke (K. N. Simiyu)

${ }^{*}$ Corresponding author

\section{To cite this article:}

Kennedy Nyongesa Simiyu, Haneya Mohammad El-Banna, Mervat Abdel Fattah, Lilian Adhiambo Omondi. Nurses' Medication Administration Errors at Medical Surgical Units. American Journal of Nursing Science. Vol. 7, No. 3, 2018, pp. 88-99. doi: 10.11648/j.ajns.20180703.12

Received: February 14, 2018; Accepted: March 5, 2018; Published: May 25, 2018

\begin{abstract}
Medication administration errors (MAEs) are among the key concepts of patient safety in clinical care settings that have long been the focus of study and exploration because they contribute directly to patient injury, death and health care costs. Medication errors are recurrent and expected to be a prolonged problem in the health care system. The administration of medication is predominantly an important part of nursing practice that has a dimension of quality of care and organizational performance. The study sought to assess nurses' medication administration errors at the general medical and surgical units. A descriptive cross sectional study design was used where stratified random sampling using the medical and surgical units as strata was used to proportionately recruit 100 Nurses. Each nurse was further observed twice during medication administration process making a total of 200 observations included in the study. Two tools were used to collect data for the current study. The interviewer administered medication administration errors questionnaire and a concealed medication administration observation checklist. Data was collected for a period of four months and analyzed using descriptive and inferential statistics to check for relations between variables. The study findings imply that the wrong rate of administration, the wrong time of administration and medication being administered after the order to discontinue was written were the highly perceived MAEs reported respectively as occurring 'most of the time' by $27 \%, 23 \%$ and $15 \%$ of the studied nurses. For observed MAEs, the wrong time error type had the highest estimated error rate of $51 \%$, followed by the documentation error at $29 \%$ and technique error at $27.5 \%$. There was statistical significant difference between the pharmacy reasons subscale of causes of MAEs and the age $(\mathrm{F}=5.465, \mathrm{p}=0.006)$, clinical experience $(\mathrm{F}=3.922, \mathrm{p}=0.011)$ and type of shift $(\mathrm{F}=2.507, \mathrm{p}=0.035)$ the nurse works most. Further, there was statistically significant mean differences between the medical and surgical units with regard to the medication packaging subscale $(\mathrm{t}=4.160, \mathrm{p}=0.044)$. The findings also revealed negative significant correlation between the observed MAEs scores and the nurses' reported scores on types of IV \& non-IV MAEs $\left(\mathrm{r}_{\mathrm{s}}=-0.266, \mathrm{p}=0.007\right)$ and the pharmacy reasons subscale $\left(\mathrm{r}_{\mathrm{s}}=-0.266, \mathrm{p}=0.046\right)$. Updating, developing, disseminating and implementing medication administration guidelines and protocols in the hospital settings is required. Nurses have to embrace the occurrence of MAEs as a patient safety indicator that should be viewed as an opportunity to learn and prevent MAEs through rationalized medication management protocols and guidelines.
\end{abstract}

Keywords: Medication Administration Errors (MAEs), Types of MAEs, Causes of MAEs, Nurses, Medical Surgical Units

\section{Introduction}

Medication errors (MEs) are probably the most common type of patient safety incidents that strike at the heart of being a nurse, which is the responsibility to do good and avoid harm. MEs have serious direct and indirect 
consequences, and are usually the result of failures in a structure of care. Direct consequences include patient harm as well as increased healthcare costs. Indirect consequences include harm to nurses in terms of professional and individual status, self-assurance, and practice [1].

Numerous definitions of what entails a medication administration error (MAE) exist in scientific literature. Most medical doctor's studies define MAE as any dose of medication that deviates from the physician's medication order as written on the patient's chart or as deviations from policies, procedures, or best practices for medication administration [2]. A meta-analysis [2] from the United Kingdom has since revealed three different definitions of medication administration errors, with over 40 sub-categories of errors and four denominators used to estimate MAEs. This lack of a generally accepted definition of MAEs, with many studies being done in different methodological settings makes comparisons difficult, and presents a potential barrier to interpreting and evaluating the transferability of interventions to reduce MAEs [3].

Every step in patient care for a nursing professional is a potential opportunity for error with some degree of threat to patient safety. The complexity of the medication administration procedure is such that errors can appear at one, some, or even all the phases between prescription and administration. In fact, the frequency of errors has been found to be $13.4 \%$ during the medication preparation process, and a high of $86.6 \%$ observed during the medication administration process. Nevertheless, most errors that actually affect a hospitalized patient occur at the bedside, when a dose of medication is incorrectly administered [4].

To avert errors, one has to detect, quantify and comprehend the problem [2]. Of all types of MEs, MAEs are least likely to be intercepted before they reach the patient because of fewer system checks since the medication is usually verified only by the person who administers the medication; by contrast, the early phases of the medication process (prescription and preparation) are mostly doublechecked by a chain of fellow health care staff $[3,5]$. Most hospital inpatients also receive more administrations than prescriptions, thus increasing the opportunities for error (OE) [2]. According to UK medication incident reports, errors at the administration phase account for the majority of patient harm and mortality [3].

Studies on MAE rates and safety have mostly been carried out in developed countries with varying reported incidences of $3.3 \%, 10 \%, 19.5 \%$ and $22.2 \%$ [5-8]. Recently, however, studies from developing countries have found very high MAE rates of $56.4 \%$ [9] and 94\% [10]. Consequently, context-specific studies on the occurrence of MAEs and related factors like patient characteristics, bed occupancy, staffing levels, nurses' qualifications, dose calculation abilities, level of hospital, unit specialties, medication administration route and interruptions, within the continent of Africa is missing [10].

MAEs have numerous causes, including both unsafe omissions and commissions or other error-provoking conditions, and often a limited number of these conditions may combine in exclusive working environments to result in an error [11]. Nurses' working experience [9], interruption of the nurses at the time of medication administration (MA) [5, $7,9,11]$, shift of MA [9], violations of medication protocols inform of slips \& lapses [11] and nurse to patient ratio [7, 9, $11,12]$ have been found to be significantly associated with occurrence of MAEs.

In Kenya, extensive search on published articles on MEs and related research yielded no specific results on MAEs. Nevertheless, Ndambuki JM et al (2013) conducted a study on quality management of medication by nurses reported that high workloads and lack of standards of quality care and procedure manuals on medication management were the main contributory factors for the poor quality of medication management in the clinical settings of most hospitals in Kenya [13].

Similarly, delays in receiving medication from pharmacy, lack of medication (medication out of stock), lack of equipment's to infuse medication, taking care of more than one patient and single nurse medication administration were perceived by majority of nurses studied as the most contributing factors to negative MA practice in the same national teaching hospital [14]. While nurses' MAEs are important indicators of patient outcomes in daily healthcare, they are an unclear \& an understudied concept in the developing countries. This study hence discusses the types and causes of MAEs and recommends the practical measures hospitals can take to improve nurses' MA management, and how to reduce MAEs.

Aim of the study is:

To determine types, and causes of MAEs by nurses working at medical and surgical units of the Moi Teaching and Referral Hospital.

\section{Materials and Method}

Design: A descriptive cross sectional design was used to collect data for this study.

Setting: The study was carried out at the medical and surgical units of the Moi Teaching and Referral Hospital, in Eldoret Kenya.

Study participants: Epi info program v 7.0 statCalc. was used to calculate the sample size of 100 nurses who were sampled and interviewed in the study. Stratified random sampling using proportionate allocation to medical and surgical wards as strata was used to proportionately recruit 45 nurses from medical wards and 55 nurses from the surgical wards.

Further, each nurse was observed twice while administering medication to two different patients, making a total of 200 medication administration process observations included in the study.

Two tools were used for data collection in the current study. Tool 1: The "Medication Administration Errors Questionnaire", adapted with permission from the authors [15] and modified to suit the study population and aims of 
the study. The tool aimed to seek input, based on clinical experience of staff nurses on medication administration errors in the medical and surgical units. It comprised of 3 parts as follows:

Part I: Types of MAEs

This part consisted of a list of 11 statements related to the types of intravenous (IV) and non-intravenous (oral, intradermal, intramuscular, topical, subcutaneous) medication administration errors.

Part II: Causes of MAEs.

This part included 29 statements on possible causes of MAEs occurring at the nurses' place of work. The statements represented medication administration error issues on: Prescribing physician communication; pharmacy processes; documentation-transcription related; nurse staffing; and medication packaging.

Part III: Socio-demographic information of Nurses

A sheet was attached to illustrate socio-demographic and occupational data of the studied nurses.

Tool 2: Nurses' medication administration errors observation checklist, was developed by the researchers after thorough review of related literature $[5,10,16-21]$. The tool aimed to observe medication administration errors committed during the medication administration process by nurses in the medical and surgical units of the hospital.

Methods:

Official approval to carry out the study was obtained from the ethical committee of the Faculty of Nursing, Alexandria University. In Kenya, formal approval was granted from the institutional research and ethics committee (IREC) and the hospital management.

A witness consent was also obtained at the beginning of the study, from the hospital administration to permit use of the concealed observation checklist on the nurses.

Tools 1 and 2 were submitted to a jury of 7 experts of medical-surgical nursing and clinical pharmacology professors in Alexandria University, to test their content validity and the necessary modifications in wording, sequencing of items and frequency and shifts of observations were modified as advised.

The reliability of the 'Medication administration errors questionnaire' was statistically tested using the Cronbach's coefficient alpha test. The tool proved to be internally reliable, with a Cronbach's coefficient alpha test of 0.868 .

A pilot study was carried out before starting the data collection process. It was applied on $10 \%$ (9) nurses, who fulfilled the inclusion criteria and drawn proportionately from the medical and surgical units. These nurses were excluded from the study subjects.

Data collection process: A written informed consent was obtained from each nurse before being interviewed by the medication administration error questionnaire.

Data were collected throughout a period of four months, from June 7 th to October $6^{\text {th }} 2017$ through:-

Interview guided questionnaire where each selected nurse was interviewed for $30-45$ minutes as guided by the medication administration errors questionnaire that contained structured questions on type of MAEs, causes of MAEs, open ended questions on prevention of MAEs and socio demographic data of the nurse.

Concealed medication administration observational checklist and record reviews after medication was checked twice through concealed observation of every nurse that had already been interviewed by the MAEs questionnaire. Each concealed observation lasted 20-30 minutes for each patient. The researcher checked for legible recording, the indicated time of administration, counter checked for dosage, form and route ordered versus the performed administration by the nurse. The observed actions and records were then checked against the set guidelines on the checklist determining if an error had been committed (checked 'Yes') or not (checked 'No').

Collected data was revised, coded and fed into the computer via the statistical package for social scientists (SPSS) version 22. All statistical analysis were done using two tailed tests. $\mathrm{P}$ value of 0.05 or less was considered significant.

Descriptive statistics including the range, median, mean and standard deviation were used to describe the study subjects' Socio-demographic and occupational characteristics.

Simple frequency tables and percentages were used to illustrate results of categorical data. One-way analysis of variance (ANOVA) and student $t$ test were used to determine whether there was any statistical significant difference in means in the various subscales of causes of MAEs. Qualitative data was analyzed using Mann Whitney U test to compare mean ranks of two groups while Kruskal Wallis test was used to compare mean ranks of more than two groups in the study. Spearman Rho correlation coefficient was used to analyze correlations between variables.

\section{Results}

\subsection{Demographic Profile of Studied Nurses}

Descriptive results (Table 1) shows that a total of 100 nurses were interviewed for the study, of which $69 \%$ were female, with majority of them $67 \%$ having a clinical experience of $1-<10$ years at the time of interview. The years of clinical experience had a range of 1-30 years with a median of 6 years.

Most of the nurses studied (84\%) were aged below 40 years, with the age group of $30-<40$ being the highly (51\%) represented in the study. The mean age of the studied nurses was 32.9 \pm 6.2 years, with a range of 21.0-54.0 years.

Majority of the nurses $64 \%$, had a diploma in nursing as the highest level of education, and majority of them $93 \%$, worked as staff nurses. In addition, most of the nurses interviewed $40 \%$ worked on a 12 hour shift per day, followed by $39 \%$ who work on day shifts. Ultimately, most of the nurses $66 \%$ had a 12 hour daily duration of work.

With regard to the frequency of administering IV/non-IV medications, $92 \%$ of the nurses frequently administered 
drugs in their daily duties. More than half of the nurses $53 \%$ did not have extra responsibility of floating between other hospital units for extra pay.
Finally $55 \%$ of the nurses interviewed, worked in the surgical units compared to $45 \%$ who worked in the medical units.

Table 1. Demographic profile of studied nurses.

\begin{tabular}{|c|c|c|}
\hline \multicolumn{2}{|c|}{ Socio-demographic and occupational characteristics of studied nurses } & \multirow{2}{*}{$\begin{array}{l}\text { Studied nurses }(\mathrm{n}=100) \text { No./\% } \\
69\end{array}$} \\
\hline Gender & Female & \\
\hline & Male & 31 \\
\hline \multirow[t]{6}{*}{ Age (years) } & $20-<30$ & 33 \\
\hline & $30-<40$ & 51 \\
\hline & $40-<50$ & 13 \\
\hline & $50-<60$ & 3 \\
\hline & Min-Max & $21.0-54.0$ \\
\hline & Mean \pm SD & $32.9 \pm 6.2$ \\
\hline \multirow[t]{5}{*}{ Duration of experience } & $1-<10$ & 67 \\
\hline & $10-<20$ & 27 \\
\hline & $20-\leq 30$ & 6 \\
\hline & Min-Max & $1.0-30.0$ \\
\hline & Median (Q1-Q3*) & $6.0(4.0-10.8)$ \\
\hline \multirow[t]{3}{*}{ Educational level } & Certificate & 1 \\
\hline & Diploma & 64 \\
\hline & Bachelor & 35 \\
\hline \multirow[t]{3}{*}{ Current clinical position } & Staff nurse & 93 \\
\hline & Head nurse/administrative & 6 \\
\hline & Others & 1 \\
\hline \multirow[t]{4}{*}{ Time of duty } & Day shift & 39 \\
\hline & Night shift & 14 \\
\hline & Rotatory shifts & 40 \\
\hline & Others & 7 \\
\hline \multirow[t]{3}{*}{ Duration of daily work } & 6 hours & 27 \\
\hline & 12 hours & 66 \\
\hline & Others & 7 \\
\hline Frequency of administering & Occasionally & 8 \\
\hline IV/non IV medications & Frequently & 92 \\
\hline \multirow{4}{*}{ Average times nurse floats (locum) between units per month } & None & 53 \\
\hline & $1-<5$ & 31 \\
\hline & $5-<10$ & 11 \\
\hline & 10 or more & 5 \\
\hline \multirow{2}{*}{ Type of nursing unit to which your responses apply } & Medical & 45 \\
\hline & Surgical & 55 \\
\hline
\end{tabular}

*Q1-Q3: Interquartile range

\subsection{Characteristics of Patients Observed During Medication Administration}

Table 2 illustrates the characteristics of the patients who were observed while receiving medication by the studied nurses.

There were 200 patients observed receiving medications. The patients were aged between 14 years and 96 years, with a mean age of $36.6 \pm 16.5$ years. The age groups of $20-<30$ and $30-<40$ had the most, $55(27.5 \%)$ and $47(23.5 \%)$ number of patients respectively.

There were more male patients $(52 \%)$ observed than female $(48 \%)$. The concealed medication administration observations were checked more (80 observations) in the evening shift than other shifts.

Of the 200 concealed medication administration observations made, $107(53.5 \%)$ had interruptions in the form of; other patients who needed care $45(42.1 \%)$, the nurse making a phone call $32(29.9 \%)$ and interruptions by other staff 30 (28\%).
Table 2. Socio demographic characteristics of patients observed during medication administration.

\begin{tabular}{llc}
\hline \multirow{2}{*}{ Characteristics of the patients } & \multicolumn{2}{c}{ Studied patients $(\mathbf{n}=\mathbf{2 0 0})$} \\
\cline { 2 - 3 } & No. & $\mathbf{\%}$ \\
\hline Gender & 104 & 52.0 \\
Male & 96 & 48.0 \\
Female & & \\
Shift of medication administration & 61 & 30.5 \\
Morning & 80 & 40.0 \\
Evening & 59 & 29.5 \\
Night & & \\
Interruption during administering of & & \\
medication & 107 & 53.5 \\
Yes & 93 & 46.5 \\
No & & \\
Source of interruption [n=107] & 32 & 29.9 \\
Phone call & 30 & 28.0 \\
Other staff & 45 & 42.1 \\
Other patient &
\end{tabular}




\subsection{Types of Medication Administration Errors}

\subsubsection{Reported Types of Intravenous (IV) and Non-IV Medication Administration Errors}

The frequency of occurrence of various types of IV and non-IV MAEs as reported by studied nurses was as follows:

The 'Wrong route/method of administration error' was perceived to 'rarely' occur by $74 \%$ of the studied nurses, contrasted to the 'wrong time of administration' error that was reported to occur 'sometimes' and 'most of the time' by $56 \%$ and $23 \%$ of the studied nurses respectively.

The 'wrong patient given medication' error, 'wrong drug administered' error and 'drug given to a patient with known allergy' error were perceived to rarely occur by $84 \%, 85 \%$ and $89 \%$ of the studied nurses respectively. Similarly, the 'medication administered after the order to discontinue was written' error, 'wrong dose administered' error, and the 'wrong fluid administered' error were also reported by nurses to 'rarely' occur at percentages of $43 \%, 59 \%$ and $60 \%$ respectively.

The 'medication is omitted' error, 'medication is given but has not been ordered by the physician' error and 'wrong rate of administration' error were perceived to 'sometimes' (more often) occur by $55 \%, 50 \%$ and $45 \%$ of the studied nurses respectively.

The reported types of IV and non-IV medication administration errors are summarized in table 3 below.

Table 3. Types of IV and Non-IV MAEs reported by the studied nurses.

\begin{tabular}{|c|c|c|c|}
\hline \multirow{2}{*}{ Types of IV and Non-IV Medication Errors } & \multicolumn{3}{|c|}{ Studied nurses $(n=100), n / \%$} \\
\hline & Rarely (0-3) & Sometimes (4-6) & Most of the time (7-10) \\
\hline Wrong route/method of administration & $74(74.0)$ & $25(25.0)$ & $1(1.0)$ \\
\hline Wrong time of administration & $21(21.0)$ & $56(56.0)$ & $23(23.0)$ \\
\hline Wrong patient given medication & $84(84.0)$ & $15(15.0)$ & $1(1.0)$ \\
\hline Wrong dose administered & $59(59.0)$ & $40(40.0)$ & $1(1.0)$ \\
\hline Wrong drug administered & $85(85.0)$ & $14(14.0)$ & $1(1.0)$ \\
\hline Medication is given, but has not been ordered by the physician & $44(44.0)$ & $50(50.0)$ & $6(6.0)$ \\
\hline Medication administered after the order to discontinue was written & $43(43.0)$ & $42(42.0)$ & $15(15.0)$ \\
\hline Given to patient with a known allergy & $89(89.0)$ & $10(10.0)$ & $1(1.0)$ \\
\hline Wrong fluid administered & $60(60.0)$ & $37(37.0)$ & $3(3.0)$ \\
\hline Wrong rate of administration & $28(28.0)$ & $45(45.0)$ & $27(27.0)$ \\
\hline
\end{tabular}

\subsubsection{Observed Medication Administration Error Rates}

The total observed errors, are presented in figure 1 below as calculated error rates (in \%) of observed MAEs during the 200 observations in the study. The wrong time error type had the highest estimated error rate of $51 \%$, followed by the documentation error at $29 \%$. The wrong patient error was found to be $0.0 \%$ in the study.

\section{observed MAE rates $(n=200)$}

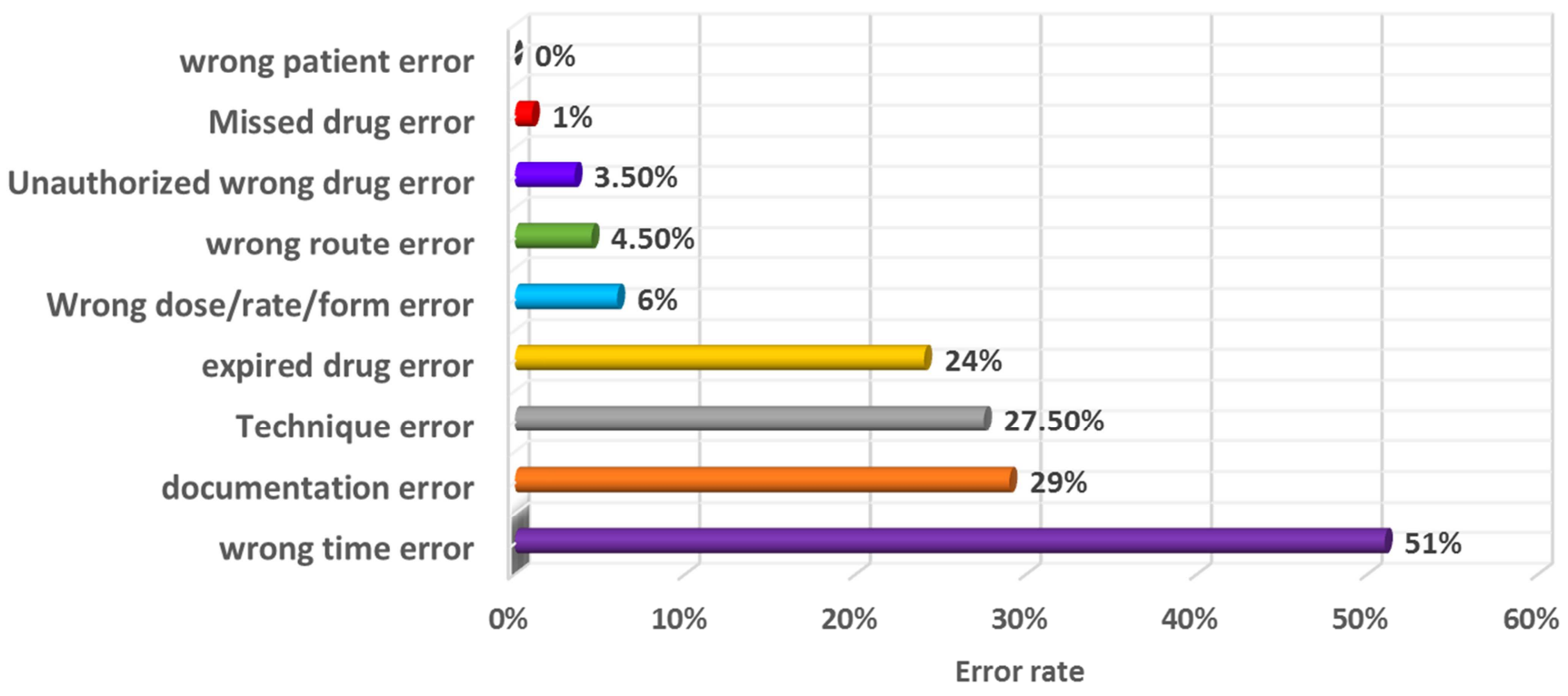

Figure 1. Error rates of the observed MAEs. 


\subsubsection{Correlation between Reported Scores of Types of IV and Non-IV MAEs with Observed MAEs Scores of the Nurses}

There was a negative significant statistical correlation between the nurses' reported scores on types of IV and nonIV MAEs and the observed MAEs scores $\left(r_{\mathrm{s}}=-0.266\right.$, $\mathrm{p}=0.007$ ) as shown in table 4 below.

Table 4. Correlation of reported scores of types of IV and non-IV MAEs with observed MAEs scores.

\begin{tabular}{lll}
\hline \multirow{2}{*}{ Questionnaire Subscales score } & \multicolumn{2}{l}{ Observed MAEs scores } \\
\cline { 2 - 3 } & Correlation coefficient, $\mathbf{r}_{\mathbf{s}}$ & P value \\
\hline Types of IV and Non-IV MAEs & -0.266 & $\mathbf{0 . 0 0 7 *}$ \\
\hline
\end{tabular}

$\mathrm{r}_{\mathrm{s}}$ : Spearman Rho correlation coefficient

*significant at $\mathrm{P} \leq 0.05$

\subsection{Causes of Medication Administration Errors}

The perceived causes of MAEs as reported by nurses are discussed as grouped into 5 subscales of the prescribing physician communication reasons, pharmacy reasons, documentation-transcription reasons, nurse staffing issues and medication packaging reasons. The frequency distributions and relations of the causes of MAEs are summarized in subsequent tables 5-7.

\subsubsection{Distribution of Perceived Causes of MAEs by Nurses}

In the Prescribing physician communication reasons subscale: The majority of the studied nurses $(\geq 60 \%)$ agreed that the following items in the subscale are possible reasons causing MAEs in the clinical settings; 'when many patients are on the same or similar medications' agreed upon by $(69 \%)$, and 'when patients are off the ward for other therapeutic or diagnostic care' agreed upon by $(60 \%)$ of the studied nurses respectively.

The table further displays that $86 \%$ of the studied nurses disagreed that 'Nurses on this unit have limited knowledge about medications' as a possible cause of MAEs. With regard to 'physician's medication orders being not legible', there was neither clear agreement (39\%) nor disagreement (39\%) by the studied nurses.

In the Pharmacy processes subscale; all items were perceived not to be possible reasons for causing medication administration errors by the studied nurses.

Regarding the Documentation-transcription related subscale, more than half of the studied nurses $(52.5 \%)$ agreed that when a 'Prescription error is made on the medication administration record sheet' it can cause MAEs. In the same subscale, however, studied nurses disagreed by $49 \%$ that the item 'On this unit, there is no easy way to look up information on medications' can cause MAEs.

For the Nurse staffing issues subscale, studied nurses were in agreement that 'Frequent substitutions of drugs with cheaper or generic drugs for brand names' and when 'Nurses are interrupted while administering medications to perform other duties' can cause MAEs by $72 \%$ and $71 \%$ of studied nurses respectively.

The nurses studied however disagreed that when 'Nurses on this unit do not adhere to the approved medication administration procedure' and when 'Nurses get pulled between teams and from other units' they can cause MAEs by $83 \%$ and $52 \%$ respectively.

Finally, in the Medication packaging reasons subscale; Nurses studied were in agreement that when 'Different medications look alike' and 'the packaging of many medications is similar' MAEs can occur as reported by $70 \%$ and $58 \%$ of the studied nurses respectively.

The studied nurses, nevertheless disagreed by $65 \%$ of the responses that when 'the names of many medications are similar', MAEs can occur.

Table 5. Causes of MAEs reported by the studied nurses.

\begin{tabular}{|c|c|c|c|c|}
\hline \multirow{2}{*}{ Subscales } & \multirow{2}{*}{ Causes of MAEs } & \multicolumn{3}{|c|}{ Studied nurses $(n=100)$, No. $(\%)$} \\
\hline & & Agree & Undecided & Disagree \\
\hline \multirow{12}{*}{$\begin{array}{l}\text { 1. Prescribing physician } \\
\text { communication issues }\end{array}$} & Physicians' medication orders are not legible. & $39(39.0)$ & $22(22.0)$ & $39(39.0)$ \\
\hline & Physicians' medication orders are not clear. & $48(48.0)$ & $14(14.0)$ & $38(38.0)$ \\
\hline & Physicians change orders frequently. & $51(51.0)$ & $17(17.0)$ & $32(32.0)$ \\
\hline & Abbreviations are used instead of writing the orders out completely. & $49(49.0)$ & $16(16.0)$ & $35(35.0)$ \\
\hline & Verbal orders are used instead of written orders. & $34(34.0)$ & $13(13.0)$ & $53(53.0)$ \\
\hline & Poor communication between nurses and physicians. & $36(36.0)$ & $19(19.0)$ & $45(45.0)$ \\
\hline & Many patients are on the same or similar medications & $69(69.0)$ & $5(5.0)$ & $26(26.0)$ \\
\hline & Unclear hospital policy and procedures regarding medication administration. & $28(28.0)$ & $19(19.0)$ & $53(53.0)$ \\
\hline & Nurses on this unit have limited knowledge about medications. & $8(8.0)$ & $6(6.0)$ & $86(86.0)$ \\
\hline & Equipment malfunctions or setting is not correctly done (e.g., IV pump). & $41(41.0)$ & $23(23.0)$ & $36(36.0)$ \\
\hline & Nurse is unaware of patient's allergy. & $32(32.0)$ & $17(17.0)$ & $51(51.0)$ \\
\hline & Patients are off the ward for other therapeutic or diagnostic care. & $60(60.0)$ & $10(10.0)$ & $30(30.0)$ \\
\hline \multirow{4}{*}{ 2. Pharmacy processes } & Pharmacy delivers incorrect doses to this unit. & $31(31.0)$ & $16(16.0)$ & $53(53.0)$ \\
\hline & Pharmacy does not prepare the medication correctly. & $30(30.0)$ & $15(15.0)$ & $55(55.0)$ \\
\hline & Pharmacy does not label the medication correctly. & $32(32.3)$ & $14(14.1)$ & $53(53.5)$ \\
\hline & Pharmacists are not available 24 hours a day. & $23(23.0)$ & $8(8.0)$ & $69(69.0)$ \\
\hline
\end{tabular}


Table 5. Cont., Causes of MAEs reported by the studied nurses.

\begin{tabular}{|c|c|c|c|c|}
\hline \multirow{2}{*}{ Subscales } & \multirow{2}{*}{ Causes of Medication Administration Errors } & \multicolumn{3}{|c|}{ Studied nurses $(\mathrm{n}=100)$, No. $(\%)$} \\
\hline & & Agree & Undecided & Disagree \\
\hline \multirow{4}{*}{$\begin{array}{l}\text { 3. Documentation- } \\
\text { Transcription related } \\
\text { Reasons }\end{array}$} & On this unit, there is no easy way to look up information on medications. & $32(32.0)$ & $19(19.0)$ & $49(49.0)$ \\
\hline & $\begin{array}{l}\text { When scheduled medications are delayed, nurses do not communicate the time when the } \\
\text { next dose is due. }\end{array}$ & $40(40.0)$ & $12(12.0)$ & $48(48.0)$ \\
\hline & Prescription Error is made on the Medication administration record sheet. & $52(52.5)$ & $17(17.2)$ & $30(30.3)$ \\
\hline & Medication administration orders are not transcribed to the Kardex correctly. & $38(38.0)$ & $14(14.0)$ & $48(48.0)$ \\
\hline \multirow{6}{*}{$\begin{array}{l}\text { 4. Nurse Staffing } \\
\text { Issues }\end{array}$} & Nurses on this unit do not adhere to the approved medication administration procedure. & $8(8.0)$ & $9(9.0)$ & $83(83.0)$ \\
\hline & Nurses are interrupted while administering medications to perform other duties. & $71(71.0)$ & $4(4.0)$ & $25(25.0)$ \\
\hline & Frequent substitution of drugs (i.e., cheaper generic for brand names). & $72(72.0)$ & $9(9.0)$ & $19(19.0)$ \\
\hline & Nurses get pulled between teams and from other units. & $36(36.0)$ & $12(12.0)$ & $52(52.0)$ \\
\hline & High patient to nurse ratio in the unit. & $54(54.0)$ & $5(5.0)$ & $41(41.0)$ \\
\hline & $\begin{array}{l}\text { All medications for one team of patients cannot be administered within an accepted time } \\
\text { frame. }\end{array}$ & $60(60.0)$ & $8(8.0)$ & $32(32.0)$ \\
\hline \multirow{3}{*}{$\begin{array}{l}\text { 5. Medication } \\
\text { Packaging Reasons }\end{array}$} & The names of many medications are similar. & $27(27.0)$ & $8(8.0)$ & $65(65.0)$ \\
\hline & Different medications look alike. & $70(70.0)$ & $3(3.0)$ & $27(27.0)$ \\
\hline & The packaging of many medications is similar. & $58(58.0)$ & $9(9.0)$ & $33(33.0)$ \\
\hline
\end{tabular}

\subsubsection{Relation of Causes of MAEs to Demographic Profile of Nurses}

When means of the causes of MAEs subscales were related to the socio-demographic and occupational characteristics of the studied nurses, there were significant statistical relationships between the pharmacy reasons subscale means with; the age of studied nurses $(\mathrm{F}=5.465, \mathrm{p}=0.006)$; clinical experience $(\mathrm{F}=3.922, \mathrm{p}=0.011)$ and the type of shift the nurse works $(\mathrm{F}=2.507$, $\mathrm{p}=0.035$ ). Similarly, there was a significant statistical relationships between the medication packaging reasons subscale means with the type of nursing unit $(\mathrm{t}=4.160, \mathrm{p}=0.044)$ as illustrated in table 6 below.

Table 6. Relation between causes of MAEs subscales and socio-demographic and occupational characteristics of nurses.

\begin{tabular}{|c|c|c|c|c|c|c|}
\hline \multirow{3}{*}{\multicolumn{2}{|c|}{$\begin{array}{l}\text { Studied nurses' socio-demographic and } \\
\text { occupational characteristics \& } \\
\text { Statistical tests }\end{array}$}} & \multicolumn{5}{|l|}{ Causes of MAE subscales } \\
\hline & & \multirow{2}{*}{$\begin{array}{l}\text { Prescribing Physician } \\
\text { communication Reasons } \\
\text { Mean } \\
\end{array}$} & \multirow{2}{*}{$\begin{array}{l}\text { Pharmacy } \\
\text { Reasons } \\
\text { Mean } \\
\end{array}$} & \multirow{2}{*}{$\begin{array}{l}\text { Documentation } \\
\text { Reasons } \\
\text { Mean } \\
\end{array}$} & \multirow{2}{*}{$\begin{array}{l}\text { Nurse staffing } \\
\text { issues } \\
\text { Mean } \\
\end{array}$} & \multirow{2}{*}{$\begin{array}{l}\text { Medication } \\
\text { Packaging Reasons } \\
\text { Mean } \\
\end{array}$} \\
\hline & & & & & & \\
\hline \multirow{2}{*}{ Gender } & female & 23.6 & 11.1 & 12.5 & 5.5 & 5.7 \\
\hline & male & 24.4 & 11.9 & 12.1 & 5.5 & 5.6 \\
\hline \multirow{2}{*}{ Student t Test } & t-value & 0.643 & 1.244 & 0.570 & 0.223 & 0.178 \\
\hline & $P$ value & 0.522 & 0.216 & 0.570 & 0.824 & 0.859 \\
\hline \multirow[t]{2}{*}{ Age in years } & 30 to 39 & 23.7 & 11.2 & 12.3 & 5.5 & 5.7 \\
\hline & $40+$ & 23.6 & 9.5 & 12.6 & 5.2 & 4.9 \\
\hline \multirow{2}{*}{ ANOVA F Test } & F value & 0.085 & 5.465 & 0.050 & 0.408 & 1.927 \\
\hline & $P$ value & 0.919 & $0.006^{*}$ & 0.951 & 0.666 & 0.151 \\
\hline \multirow{4}{*}{$\begin{array}{l}\text { Clinical } \\
\text { experience since } \\
\text { graduation }\end{array}$} & $<5$ & 24.9 & 12.6 & 12.8 & 5.7 & 6.3 \\
\hline & 5 to 9 & 23.2 & 11.4 & 12.1 & 5.6 & 5.6 \\
\hline & 10 to 14 & 23.4 & 10.2 & 12.2 & 5.1 & 5.2 \\
\hline & $15+$ & 23.8 & 10.0 & 12.7 & 5.3 & 5.3 \\
\hline ANOVA F Test & $P$ value & 0.644 & $0.011^{*}$ & 0.809 & 0.608 & 0.217 \\
\hline \multirow{3}{*}{$\begin{array}{l}\text { Highest nursing } \\
\text { education level }\end{array}$} & certificate & 25.0 & 6.0 & 16.0 & 6.0 & 4.0 \\
\hline & diploma & 24.1 & 11.4 & 12.5 & 5.3 & 5.6 \\
\hline & bachelor of nursing & 23.3 & 11.3 & 12.2 & 5.9 & 5.9 \\
\hline \multirow{2}{*}{ ANOVA F Test } & F value & 0.225 & 1.587 & 0.745 & 1.489 & 0.669 \\
\hline & $P$ value & 0.799 & 0.210 & 0.478 & 0.231 & 0.514 \\
\hline \multirow{4}{*}{$\begin{array}{l}\text { Shift nurse } \\
\text { works most }\end{array}$} & Day shift & 25.4 & 12.4 & 13.4 & 6.3 & 5.8 \\
\hline & Night shift & 22.1 & 10.4 & 11.7 & 5.1 & 5.3 \\
\hline & Rotatory shifts & 23.3 & 10.6 & 12.1 & 5.1 & 5.9 \\
\hline & $\begin{array}{l}\text { Other (administrative } \\
\text { shifts) }\end{array}$ & 21.7 & 11.0 & 12.1 & 4.9 & 4.7 \\
\hline \multirow{2}{*}{ ANOVA F Test } & $\mathrm{F}$ value & 1.240 & 2.507 & 0.640 & 2.021 & 1.237 \\
\hline & $P$ value & 0.297 & $0.035^{*}$ & 0.670 & 0.083 & 0.298 \\
\hline \multirow{2}{*}{$\begin{array}{l}\text { Type of nursing } \\
\text { unit }\end{array}$} & Medical unit & 24.16 & 11.82 & 11.98 & 5.62 & 6.16 \\
\hline & Surgical unit & 23.56 & 10.89 & 12.75 & 5.38 & 5.33 \\
\hline
\end{tabular}




\subsubsection{Correlation Between Causes of MAEs and Observed MAEs Scores}

There was a negative significant correlation when the reported nurses' scores of pharmacy reasons subscale were correlated with the observed MAEs scores $\left(\mathrm{r}_{\mathrm{s}}=-0.266, \mathrm{p}=0.046\right)$.

However, there was no significant correlations when the other subscales of causes of MAEs were correlated with the observed MAEs scores of the studied nurses as summarized in table 7 below.

Table 7. Correlations between reported scores of causes of MAEs and observed MAEs scores of the studied nurses.

\begin{tabular}{lll}
\hline \multirow{2}{*}{ Questionnaire Subscales score } & Observed MAEs scores & P value \\
\cline { 2 - 3 } & Correlation coefficient, $\mathbf{r}_{\mathbf{s}}$ & \\
\hline Causes of MAEs subscales & & 0.070 \\
\hline Prescribing physician communication issues & -0.182 & $\mathbf{0 . 0 4 6 *}$ \\
Pharmacy processes & -0.200 & 0.309 \\
Documentation-Transcription related issues & -0.103 & 0.138 \\
Nurse staffing issues & -0.149 & 0.190 \\
Medication packaging reasons & -0.132 & \\
\hline
\end{tabular}

$\mathrm{r}_{\mathrm{s}}$ : Spearman Rho correlation coefficient

*significant at $\mathrm{P} \leq 0.05$

\subsubsection{Occurrence of MAEs Between Medical and Surgical Units}

The nurses' MAE scores of the medical and surgical units for each of the sub items was calculated and statistically related. There was no significant statistical relationship noted between the medical and surgical units' nurses' scores on the types of IV and Non-IV MAEs and the causes of MAEs as presented in table 8 below.

Table 8. Relation of Nurses' scores of reported types of IV and Non-IV MAEs, and causes of MAEs between the medical and surgical units.

\begin{tabular}{llc}
\hline $\begin{array}{l}\text { Reported nurses' MAEs scores (Questionnaire sub } \\
\text { items) }\end{array}$ & \multicolumn{2}{l}{ MAEs Score of nurses in specific Nursing units (Q1-Q3) } \\
\cline { 2 - 3 } Tedical $(\mathbf{n}=\mathbf{4 5})$ & \multicolumn{2}{c}{ Surgical $(\mathbf{n}=\mathbf{5 5})$} \\
\hline Types of IV and Non-IV MAEs & $22.7(13.6-27.3)$ & $22.7(18.2-31.8)$ \\
Causes of MAEs & $31.0(13.8-37.9)$ & $27.6(19.0-36.2)$ \\
Prescribing physician communication issues & $29.2(16.7-37.5)$ & $29.2(20.8-41.7)$ \\
Pharmacy processes & $20.0(0.0-30.0)$ & $20.0(10.0-40.0)$ \\
Documentation-Transcription related issues & $33.3(12.5-41.7)$ & $25.0(16.7-33.3)$ \\
Nurse staffing issues & $33.3(16.7-41.7)$ & $33.3(16.7-50.0)$ \\
Medication packaging reasons & $33.3(0.0-41.7)$ & $33.3(16.7-50.0)$ \\
\hline
\end{tabular}

Q1-Q3: Interquartile range; Z: Mann Whitney $\mathrm{U}$ test; *significant at $\mathrm{P} \leq 0.05$

\section{Discussion}

Medication errors are recurrent and expected to be a prolonged problem in the health care system. Nurses are inevitably crucial to medication administration errors (MAEs) in any clinical settings. While nursing fundamentally aims to ensure patient safety and at the very least do no harm to the patient, medication errors have become common causes of harm to patients with up to $6.5 \%$ of patients in clinical settings affected [22]. In fact a hospitalized patient typically experiences 1 medication error per day, most often during medication administration [23].

Medication errors pose a great concern for the hospitals, patients and healthcare professionals. Consequently, in recent years there have been concerted efforts through clinical research to explore medication errors in terms of the types, causes/risk factors, monitoring, reporting and prevention. However, since the healthcare field is under continuous therapeutic, technological and pharmacological advancement, medication errors remain a challenge [24].

In the current study, perceived types and observed types of IV and non-IV MAEs by nurses were studied. The highest perceived rates of errors occurring in the present study were the 'wrong rate of administration' error, 'wrong time' of administration errors and 'medication being administered after the order to discontinue had been written', reported as commonly occurring 'most of the time'. Further, relatively lower frequencies were perceived to occur for MAEs of 'medication omitted' and 'medication given, but has not been ordered by the physician' respectively. These findings closely compare to other studies done in similar clinical settings of hospitals in developing countries like Oshikoya et al. (2013) reported rates of $40 \%, 24 \%$ and $16 \%$ for wrong timing, wrong drug and wrong frequency of administration respectively [25], while Feleke, Mulatu \& Yesmaw (2015) reported an $8.3 \%$ error rate for omitted drugs and $1.1 \%$ for unauthorized drugs [9].

Similarly, during concealed observation of nurses administering drugs, the wrong time error, documentation error, technique error and expired drug error had the highest number of nurses observed committing this errors, translating to an observed error rate of $51 \%, 29 \%, 27.5 \%$ and $24 \%$ respectively, when calculated using 200 observations as the opportunities for error (OE) in the study. The wrong time error finding was the most prevalent during observation of nurses administering medications in the current study. This finding compares closely with most MAEs studies done in similar settings including Alemu, Belachew \& Yimam 
(2017), who reported that failure to administer medications at the right time was the second most commonly perpetrated incident [26], while a similar study in south Africa found that the most common types of errors were wrong-time errors at $43 \%$ and errors of omission at $41 \%$, followed by wrong-dose errors $12 \%$ [10].

In Egypt, Al-Tehewy et al (2016) found an overall MAE rate of $37.68 \%$ (per hundred error opportunities), with the most frequent errors being wrong documentation (90.96\%) and wrong technique $(78.90 \%)$, while the least was wrong patient $(0.05 \%)$ comparable to the present study [21]. Elsewhere, in Saudi Arabia, a study using a MAEs questionnaire similarly reported that the most common NonIV MAEs were wrong time, followed by wrong dose and medication omitted while the most common IV MAEs were wrong rate, followed by wrong time, and wrong dose [27]. Furthermore, in an international systematic review of MAE studies, Keers et al. (2013) noted that of the number of studies reporting the number of timing errors $(n=64)$, this was the most common error subtype, being reported in 51 $(79.7 \%)$ studies as one of the three most common error subtypes identified followed by omission $(n=10,76.9 \%)$, wrong dosage $(\mathrm{n}=9,69.3 \%)$, and unauthorized drug $(\mathrm{n}=7$, $53.8 \%$ ) errors [28]. Similarly, in a systematic review of literature relating to MAEs in Southeast Asian countries, it was found that the most frequently reported types of administration errors were incorrect time, omission error and incorrect dose [29].

However while the sequence of commonly occurring errors compares to the current study and other developing countries findings, lower error rates have sometimes been reported in the developed clinical settings. For instance a study in Spain [4] reported error rates of omitted drugs 1.4\%, wrong infusion speed $1.2 \%$ and wrong dose $0.8 \%$ while another study in France [19] had very high wrong time error rates of $72.6 \%$ but lower rates for omission error $14 \%$, unauthorized drug error $3.7 \%$ and wrong dose error $1.9 \%$. In the UK [30] an omitted doses error rate of $16.83 \%$ was reported. In essence, the commonality of wrong time errors across all clinical settings in the world can be viewed as a product of institutional systems deficiencies such as workload or staffing issues, and may therefore indicate a widespread systems issue which is worldwide.

The present study had no significant statistical relationships when the MAE observation scores were related to the demographic data and occupational characteristics of the studied nurses as well as the observed interruptions and other patient characteristics. This might mean that all nurses studied were equally vulnerable to the reported levels of MAEs regardless of their demographic data and other characteristics. Similar findings have been reported before by Al-Youssif, Mohamed \& Mohamed (2013) while studying nurses' experiences of MAEs [27]. In contrast, however staffing characteristics are extensively studied and have been identified as causative to unpredictability in the clinical area including MAEs [7, 9, 31, 32].

One of the key findings of the present study was that nurses perceived mostly low percent for non-IV and IV MAEs (reported as 'most of the time' in table 3), that had negative statistically significant correlation $\left(r_{\mathrm{s}}=-0.266\right.$, $\mathrm{p}=0.007$ ) with the observation score of mean ranks of errors. These results can be attributed to the variation in sensitivity of the methods used to collect data; that is observation of errors compared to perception of errors by the nurses. The result may further underline the possible under reporting or recognition of errors by nurses in the clinical areas. Other studies have reported such variations and recommended use of several MAEs detection methods based on limitations and strengths of each method to uncover diverse and representative MAEs information [3, 5, 28, 33].

Perceived causes of MAEs.

The medication process is significantly prone to errors, especially during prescription and drug administration. Although the causes of MAEs are reportedly various, studies on causes or factors contributing to MAEs remain inconclusive and sometimes lack a legitimate nurses' perspective. Therefore, nurses' perception for these reasons can enhance understanding of these factors [34]. The present study discusses findings according to the five subscales on causes of MAEs as suggested by Wakefield, Uden-Holman \& Wakefield (2005) during the development of the adapted tool 1 used in the present study [15].

With regard to the prescribing physician communication subscale, our results revealed that almost three quarters of nurses perceived that when 'many patients are put on the same or similar medications' as well as over half reporting that when 'patients are off the ward for other therapeutic or diagnostic care at the time of medication administration', MAEs are bound to occur. Conversely, over three quarters of nurses disagreed when asked if 'nurses on the unit had limited knowledge about medications' as a possible cause of MAEs.

These findings are relevant and consistent with previous studies that have since reported that a high volume of similar drugs to be administered increases the nurses' task in the medication administration process of; finding, identifying and verifying medicines which predisposes to MAEs $[9,19$, 35]. Similarly, disruptions and/or distractions increases the chances of errors in nursing work so that when patients are off the ward for other therapeutic or diagnostic care at the time of medication administration, it's been found to contribute to missed dosages or incorrect time MAEs occurrence [29, 36-38].

Further findings of the present study illustrated that over half of the study participants disagreed with all four items in the pharmacy processes subscale as a possible cause of MAEs. It's hence indicative that there was a negative statistically significant correlation $\left(\mathrm{r}_{\mathrm{s}}=-0.200, \mathrm{p}=0.046\right)$ between the pharmacy reasons subscale and the mean ranks of observed MAEs in the current study. The negative correlation results support a growing number of previous studies [34, 39] that have found pharmacy factors not considered among those factors that may contribute to medication administration errors at health care settings. 
In addition, other statistically significant differences were found when the pharmacy processes subscale mean scores were related to the within group means of the nurses' age $(F=5.465, p=0.006)$, years of clinical experience $(F=3.922$, $\mathrm{p}=0.011)$ and the shift that the nurse works most $(\mathrm{F}=2.507$, $\mathrm{p}=0.035$ ) using the analysis of variance (ANOVA) test. This findings indicate the mean score variations within the nurses' socio-demographic characteristics on perceptions of pharmacy reasons as a cause of MAEs. The within group differences may additionally, indicate how undecided nurses are about pharmacy processes as possible causes of MAEs.

A substantial number of studies have identified that age of the nurse and working experience are significantly associated with MAEs [9, 37, 40]. This can be explained by the fact that MA is one of the nurse's practices that improves with age and experience. In addition, nurses with more years and work experience have greater knowledge and skills related to MA as well as very familiar with different types of medications [9].

The medication packaging reasons subscale revealed that almost three quarters and over half of the nurses perceived that when different medications look alike and when the packaging of many medications is similar respectively, MAEs can occur. A further comparison of the medication packaging subscale mean scores between the medical and surgical units revealed statistically significant mean differences between the two units $(\mathrm{t}=4.160, \mathrm{p}=0.044)$. Several studies $[11,26,41]$ intimate that once a medication has been unpackaged, from its original packet it can easily be mistaken with other look alike medications and therefore it should be immediately dispensed to the patient to avoid MAEs.

Concerning the nurse staffing issues subscale, the current study found that almost three quarters of nurses interviewed perceived 'frequent substitutions of drugs with cheaper or generic drugs for brand names' to be a possible cause of MAEs. Further when 'nurses are interrupted during administering medications to perform other duties' was reported as another cause of MAEs by majority of nurses interviewed. Similarly over half of the nurses studied noted that 'all medications for one team of patients could not be administered within an accepted time frame' as well as 'high patient to nurse ratio in the unit situations' are likely to cause MAEs in the clinical area. Conversely, most of the studied nurses disagreed that their not adhering to approved medication administration procedures and their getting pulled between teams and from other units can predispose to occurrence of MAEs.

While no statistically significant differences were realized when the nurse staffing issues subscale was related to independent variables, the basic findings on the items in the subscale are well researched and documented causes of MAEs. For instance, distractions or interruptions [7, 42], impractical policies/procedures [28], understaffing [19], higher number of patients under care of the nurse $[9,19]$, high volume of generic drugs substitution [43, 44] and large number of medicines scheduled at peak times [35], have been reported to predispose nurses to inability to facilitate, identify, verify and correctly administer scheduled drugs.

Regarding the documentation-transcription related subscale, results of the current study showed that nurses did not perceive most of the items as causes of MAEs including: 'lack of an easy way to look up information on medications'; 'when scheduled medications are delayed, nurses do not communicate the time when the next dose is due'; and when 'medication administration orders are not transcribed to the Kardex correctly'. However, about half of the nurses studied perceived a 'prescription error made on the medication administration record sheet' to be a possible cause of MAEs.

Studies previously done elsewhere, have similarly found erroneous prescriptions among the most contributing factors to MAEs, where nurses experience drug errors occurring when a physician prescribes a wrong dose $[38,45]$ as well as when physicians allot insufficient time to discuss suggested care with nurses. Similar to the present study; Hammoudi, Ismaile \& Abu-Yahya (2017) recently found low agreement rates given in response to questions on transcribing documentation factors in their study [41], indicating the low perception or consideration by nurses of the scale items as a possible cause of MAEs.

\section{Conclusion}

Based on the current study findings, the wrong time of administration error was the most prevalent among the studied nurses. It mostly included failure to administer a dosage at the right time or rather delaying a dose by over 30 minutes from the ordered/intended time of administration. The delay in the current study was more often observed to be more than 1 hour after intended time and some doses were observed being given more than 2 hours earlier as some nurses combined the doses in one drug round during the evening shift. The other prevalent types of IV and non-IV MAEs revealed in the present study included the wrong rate of administration error, documentation errors and technique errors.

The study also found negative statistical significant correlations between the perceived low percentages of IV and non-IV MAEs and the mean ranks of the observed MAEs scores. This was attributed to the variation in sensitivity of the data collection methods, it may as well indicate under reporting or low recognition of errors by the studied nurses.

The current study further found that high volume of patients or similar/look-alike drugs, distractions during medication administration, frequent substitutions of drugs with cheaper or generic drugs coupled with erroneous prescriptions were reported to predispose to MAEs, through increasing nurses' task of facilitating, identifying, verifying and correctly administering scheduled drugs.

Nurses however have to embrace the fact that occurrence of MAEs is a patient safety indicator, and not that a nurse is doing a bad job. The MAEs should be viewed as opportunities to learn and prevent such errors from occurring again. 
The study recommends a safe working environment through rationalized medication management protocols and nurse to patient ratios conducive for patient care delivery and reduction of MAEs. Further, a multi-design research on MAEs with causal effects measurements and recommendations to establish interventions for the identified types and causes of MAEs is suggested.

\section{References}

[1] Mayo AM, Duncan D. Nurse perceptions of medication errors: what we need to know for patient safety. J Nurs Care Qual 2004; 19 (3):209-17.

[2] McLeod MC, Barber N, Franklin BD. Methodological variations and their effects on reported medication administration error rates. BMJ Qual Saf 2013; 22 (4):278-89.

[3] Härkänen $\mathrm{M}$, Saano S, Vehviläinen-Julkunen K. Using incident reports to inform the prevention of medication administration errors. J Clin Nurs 2017; 1-14.

[4] Rodriguez-Gonzalez CG, Herranz-Alonso A, Martin-Barbero ML, Duran-Garcia E, Durango-Limarquez MI, HernándezSampelayo P, et al. Prevalence of medication administration errors in two medical units with automated prescription and dispensing. J Am Med Informatics Assoc 2012; 19 (1):72-8.

[5] Härkänen M, Ahonen J, Kervinen M, Turunen H, VehviläinenJulkunen $\mathrm{K}$. The factors associated with medication errors in adult medical and surgical inpatients: A direct observation approach with medication record reviews. Scand J Caring Sci 2015; 29 (2).

[6] Bates DW. Getting in step: Electronic health records and their role in care coordination. J Gen Intern Med 2010; 25 (3):174 6.

[7] Cottney A, Innes J. Medication-administration errors in an urban mental health hospital: A direct observation study. Int J Ment Health Nurs 2015; 24 (1):65-74.

[8] Yung HP, Yu S, Chu C, Hou IC, Tang FI. Nurses' attitudes and perceived barriers to the reporting of medication administration errors. J Nurs Manag 2016; 24 (5):580-8.

[9] Feleke SA, Mulatu MA, Yesmaw YS. Medication administration error: magnitude and associated factors among nurses in Ethiopia. BMC Nurs 2015; 14 (1):53.

[10] Blignaut AJ, Coetzee SK, Klopper HC, Ellis SM. Medication administration errors and related deviations from safe practice: An observational study. J Clin Nurs 2017; 1-14.

[11] Keers RN, Williams SD, Cooke J, Ashcroft DM. Causes of medication administration errors in hospitals: A systematic review of quantitative and qualitative evidence. Drug Saf 2013; 36 (11):1045-67.

[12] You MA, Choe MH, Park GO, Kim SH, Son YJ. Perceptions regarding medication administration errors among hospital staff nurses of South Korea. Int J Qual Heal Care 2015; 27 (4):276-83.

[13] Ndambuki JM, Odhiambo E, Chege M, Mirie W. Factors influencing quality management of medication by nurses at Kenyatta National Hospital Paediatric wards. Nairobi, Kenya. J Biol Agric Healthc 2013; 3 (18):93-9.
[14] Kimeu VK. Factors Influencing Medication Administration Practice among Nurses at Kenyatta National Hospital General Critical Care Unit. Unpubl masters thesis 2015.

[15] Wakefield BJ, Uden-Holman T, Wakefield DS. Development and Validation of the Medication Administration Error Reporting Survey. Adv Patient Saf 2005; 4:475-89.

[16] Bifftu BB, Dachew BA, Tiruneh BT, Beshah DT. Medication administration error reporting and associated factors among nurses working at the University of Gondar referral hospital, Northwest Ethiopia, 2015. BMC Nurs 2016; 15 (1):43.

[17] Mostafaei D, Marnani AB, Esfahani HM, Estebsari F, Shahzaidi S, Jamshidi E, et al. Medication errors of nurses and factors in refusal to report medication errors among nurses in a teaching medical center of iran in 2012. Iran Red Crescent Med J 2014; 16 (10):e16600.

[18] McBride-Henry K, Foureur M. Medication administration errors: Understanding the issues. Aust J Adv Nurs 2006; 23 (3):33-41.

[19] Berdot S, Sabatier B, Gillaizeau F, Caruba T, Prognon P, Durieux P. Evaluation of drug administration errors in a teaching hospital. BMC Heal Serv Res 2012; 12:60.

[20] Acheampong F, Tetteh AR, Anto BP. Medication Administration Errors in an Adult Emergency Department of a Tertiary Health Care Facility in Ghana. J Patient Saf 2015; 12 (4):1.

[21] Al Tehewy M, Fahim H, Gad NI, El Gafary M, Rahman SA. Medication Administration Errors in a University Hospital. J Patient Saf 2016; 12 (1):34-9.

[22] Ofosu R, Jarrett P. Reducing nurse medicine administration errors. Nurs Times 2015; 3 (20):12-4.

[23] Durham ML, Suhayda R, Normand P, Jankiewicz A, Fogg L. Reducing Medication Administration Errors in Acute and Critical Care. JONA J Nurs Adm 2016; 46 (2):75-81.

[24] Karavasiliadou S, Athanasakis E. An inside look into the factors contributing to medication errors in the clinical nursing practice. Heal Sci J 2014; 8 (1):32-44.

[25] Oshikoya KA, Oreagba IA, Ogunleye OO, Senbanjo IO, MacEbong GL, Olayemi SO. Medication administration errors among paediatric nurses in Lagos public hospitals: An opinion survey. Int J Risk Saf Med 2013; 25 (2):67-78.

[26] Alemu W, Belachew T, Yimam I. International Journal of Africa Nursing Sciences Medication administration errors and contributing factors: A cross sectional study in two public hospitals in Southern Ethiopia. Int J Africa Nurs Sci 2017; 7 (November 2016):68-74.

[27] Al-youssif SA, Mohamed LK, Mohamed NS. Nurses' Experiences toward Perception of Medication Administration Errors Reporting. J Nurs Heal Sci 2013; 1 (4):56-70.

[28] Keers RN, Williams SD, Cooke J, Ashcroft DM. Prevalence and nature of medication administration errors in health care settings: A systematic review of direct observational evidence. Ann Pharmacother 2013; 47 (2):237-56.

[29] Salmasi S, Khan TM, Hong YH, Ming LC, Wong TW. Medication errors in the Southeast Asian countries: A systematic review. PLoS One 2015; 10 (9):e0136545.

[30] Shandilya S, Nizamuddin K, Faisal MW aqar, Noor S, Abraham S. Omitted medications: a continuing problem. Clin Med 2015; 15 (1):12-4. 
[31] Fathi A, Hajizadeh M, Moradi K, Zandian H, Dezhkameh M, Kazemzadeh S, et al. Medication errors among nurses in teaching hospitals in the west of Iran : what we need to know about prevalence, types, and barriers to reporting. Epidemiol Health 2017; 39:e201702.

[32] Flynn L, Liang Y, Dickson GL, Xie M, Suh DC. Nurses' Practice Environments, Error Interception Practices, and Inpatient Medication Errors. J Nurs Scholarsh 2012; 44 (2):180-6.

[33] Härkänen $\mathrm{M}$, Turunen $\mathrm{H}$, Vehviläinen-Julkunen $\mathrm{K}$. Differences Between Methods of Detecting Medication Errors: A Secondary Analysis of Medication Administration Errors Using Incident Reports, the Global Trigger Tool Method, and Observations. J Patient Saf 2016; 0 (0):1-9.

[34] Aboshaiqah AE. Nurses' Perception of Medication Administration Errors. Am J Nurs Res 2014; 2 (4):63-7.

[35] Jones JH, Treiber L. When the 5 Rights Go Wrong. J Nurs Care Qual 2010; 25 (3):240-7.

[36] Westbrook JI, Woods A, Rob MI, Dunsmuir WTM, Day RO. Association of Interruptions With an Increased Risk and Severity of Medication Administration Errors. Arch Intern Med 2010; 170 (8):683.

[37] Westbrook JI, Rob MI, Woods A, Parry D. Errors in the administration of intravenous medications in hospital and the role of correct procedures and nurse experience. BMJ Qual Saf 2011; 20 (12):1027-34.

[38] Pirinen H, Kauhanen L, Danielsson-ojala R, Lilius J, Tuominen I, Rodríguez ND, et al. Registered Nurses ,
Experiences with the Medication Administration Process. Adv Nurs 2015; 2015 (1):1-10.

[39] Mrayyan MT. Reported incidence, causes, and reporting of medication errors in teaching hospitals in Jordan: A comparative study. Contemp Nurse 2012; 41 (2):216-32.

[40] Fasolino T, Snyder R. Linking nurse characteristics, team member effectiveness, practice environment, and medication error incidence. J Nurs Care Qual 2012; 27 (2):E9-16.

[41] Hammoudi BM, Ismaile S, Abu Yahya O. Factors associated with medication administration errors and why nurses fail to report them. Scand J Caring Sci 2017; (9):5-8.

[42] Hayes C, Jackson D, Davidson PM, Power T. Medication errors in hospitals: A literature review of disruptions to nursing practice during medication administration. J Clin Nurs 2015; 24 (21-22):3063-76.

[43] Lan YH, Wang KWK, Yu S, Chen IJ, Wu HF, Tang FI. Medication errors in pediatric nursing: Assessment of nurses' knowledge and analysis of the consequences of errors. Nurse Educ Today 2014; 34 (5):821-8.

[44] Tang FI, Sheu SJ, Yu S, Wei IL, Chen CH. Nurses relate the contributing factors involved in medication errors. J Clin Nurs 2007; 16 (3):447-57.

[45] Wang HF, Jin JF, Feng XQ, Huang X, Zhu LL, Zhao XY, et al. Quality improvements in decreasing medication administration errors made by nursing staff in an academic medical center hospital: A trend analysis during the journey to Joint Commission International accreditation and in the postaccreditation era. Ther Clin Risk Manag 2015; 11:393-406. 